Contract No. and Disclaimer:

This manuscript has been authored by Savannah River Nuclear Solutions, LLC under Contract No. DE-AC09-08SR22470 with the U.S. Department of Energy. The United States Government retains and the publisher, by accepting this article for publication, acknowledges that the United States Government retains a non-exclusive, paid-up, irrevocable, worldwide license to publish or reproduce the published form of this work, or allow others to do so, for United States Government purposes. 


\title{
The Effect of ${ }^{3} \mathrm{He}$ on Low Pressure Hydride Absorption Measurements with Tritium
}

\author{
G. C. Staack and J. E. Klein \\ Savannah River National Laboratory, Aiken, South Carolina 29808 USA, Gregory.Staack@srnl.doe.gov
}

\begin{abstract}
Absorption isotherm data exists for a wide variety of hydrogen-metal systems. When working with high purity gases, appropriately sized equipment, and hydrides with equilibrium pressures above several hundred Pa, data collection is relatively straightforward. Special consideration must be given to experiments involving low equilibrium pressure hydrides, as even sub-ppm levels of gas impurities can generate partial pressures many times greater than the equilibrium pressures to be measured. Tritium absorption experiments are further complicated by the continuous generation of helium-3. The time required to transfer and absorb a known quantity of tritium onto a sample ultimately limits the minimum pressure range that can be studied using the standard technique. Equations are presented which show the pressure of helium-3 in a sample cell based on the amount of tritium to be absorbed, the sample cell volume and temperature, and the decay time of tritium. Sample calculations for zirconium show that at $300^{\circ} \mathrm{C}$, the estimated helium-3 pressure in the cell will be equal to the hydrogen absorption pressure after only milliseconds of tritium decay. An alternate method is presented that permits the collection of equilibrium data at pressures orders of magnitude lower than possible using a direct approach
\end{abstract}

\section{INTRODUCTION}

Absorption isotherm collection on a typical Sievert's type manifold consists of filling a charge volume (CV) to a certain pressure and opening a valve connecting the $\mathrm{CV}$ to a sample cell (SC) containing the hydride. After a stable pressure (assumed to be the equilibrium pressure) is obtained, the $\mathrm{SC}$ is isolated from $\mathrm{CV}$, additional gas introduced into the $\mathrm{CV}$, and the process repeated. By knowing the volume, pressure, and temperature of the $\mathrm{CV}$ and SC before and after opening the connecting valve, the amount of gas absorbed/reacted with the sample can be calculated by mass balance. The isotherm is constructed to correlate sample loading $(\mathrm{Q} / \mathrm{M}$ - hydrogen isotope-tometal ratio) with measured equilibrium pressures.

Impurities in the absorbing gas that are not absorbed or reacted with the hydride/getter will accumulate in the
$\mathrm{SC}$ void space and contribute to the measured pressure. The impurity partial pressure may produce an artificially high "equilibrium" absorption pressure, but whether or not it is a significant fraction of the total pressure depends on a number of factors, one of which is the equilibrium pressure of the hydride. The impact of impurities on the apparent hydride absorption pressure becomes greater as the true absorption pressure of the hydride decreases. For some low pressure hydride/getter systems, the impurity partial pressure in the sample cell can easily exceed the absorption equilibrium pressure of the material being tested.

The purpose of this paper is to present the equations used to calculate in the impurity partial pressure in a SC void volume as a result of tritium decay, perform a sample calculation for a low pressure hydride/getter material and present an alternate technique that will allow the measurement of both absorption and desorbtion equilibrium data on low pressure hydrides using tritium.

\section{MASS BALANCE}

The impact of inerts on absorption pressure measurements for hydride systems will be analyzed by use of mass balance equations. The hydrogen isotope mass balance is given by

$$
\begin{aligned}
& \frac{P_{C V, i} V_{C V}\left(1-x_{C V, i}\right)}{R T_{C V, i}}+\frac{P_{S C, i} V_{S C, i}\left(1-x_{S C, i}\right)}{R T_{S C, i}}+n_{i}= \\
& \frac{P_{C V, f} V_{C V}\left(1-x_{C V, f}\right)}{R T_{C V, f}}+\frac{P_{S C, f} V_{S C, f}\left(1-x_{S C, f}\right)}{R T_{S C, f}}+n_{f}
\end{aligned}
$$

and the inert mass balance is given by Eq. 2 where $\mathrm{P}$ is pressure, $\mathrm{V}$ is volume, $\mathrm{T}$ is temperature, $\mathrm{R}$ is the ideal gas constant, $\mathrm{n}$ is the mole of hydrogen isotopes $\left(\mathrm{Q}_{2}\right)$ in the hydride, and $\mathrm{x}$ is the gas phase inert mole fraction. The subscripts $\mathrm{CV}, \mathrm{SC}$, i, and $\mathrm{f}$, refer to the charge volume, sample cell, initial conditions, and final conditions, respectively. 


$$
\begin{aligned}
& \frac{P_{C V, i} V_{C V} x_{C V, i}}{R T_{C V, i}}+\frac{P_{S C, i} V_{S C, i} x_{S C, i}}{R T_{S C, i}} \\
& =\frac{P_{C V, f} V_{C V} x_{C V, f}}{R T_{C V, f}}+\frac{P_{S C, f} V_{S C, f} x_{S C, f}}{R T_{S C, f}}
\end{aligned}
$$

For isothermal conditions and no gas mixing between the two volumes, $\mathrm{T}_{\mathrm{CV}, \mathrm{i}}=\mathrm{T}_{\mathrm{CV}, \mathrm{f}}=\mathrm{T}_{\mathrm{CV}}, \mathrm{T}_{\mathrm{SC}, \mathrm{i}}=\mathrm{T}_{\mathrm{SC}, \mathrm{f}}=\mathrm{T}_{\mathrm{SC}}$, and $\mathrm{x}_{\mathrm{CV}, \mathrm{i}}=\mathrm{x}_{\mathrm{CV}, \mathrm{f}}=\mathrm{x}_{\mathrm{CV}}$, and Equation 1 becomes

$$
\begin{aligned}
& \frac{\Delta V_{S T P} P_{S T P}}{T_{S T P}}+\frac{P_{S C, f} V_{S C}\left(1-x_{S C, f}\right)}{T_{S C}}-\frac{P_{S C, i} V_{S C}\left(1-x_{S C, i}\right)}{T_{S C}} \\
& =\frac{\left(P_{C V, i}-P_{C V, f}\right) V_{C V}\left(1-x_{C V}\right)}{T_{C V, i}}
\end{aligned}
$$

where $\Delta \mathrm{V}_{\text {STP }}$ represents the amount $\left(\mathrm{Pa}-\mathrm{m}^{3}\right)$ of hydrogen isotopes absorbed by the sample under standard conditions $\left(\mathrm{P}_{\mathrm{STP}}=101.3 \mathrm{kPa}\right.$ and $\left.\mathrm{T}_{\mathrm{STP}}=0^{\circ} \mathrm{C}\right)$ Similarly, Equation 2 becomes

$$
P_{S C, f} x_{S C, f}=P_{S C, i} x_{S C, i}+\frac{\left(P_{C V, i}-P_{C V, f}\right) V_{C V}}{T_{C V}} \cdot \frac{T_{S C} x_{C V}}{V_{S C}}
$$

To examine the impact of inerts on the measured absorption pressure, assume that all hydrogen isotopes in the $\mathrm{SC}$ void space are gettered by sample: $\left(\mathrm{x}_{\mathrm{SCi}}=\mathrm{x}_{\mathrm{SCf}}=1\right.$. Furthermore, assume for low levels of inerts in the charge volume, the term $\left(1-\mathrm{x}_{\mathrm{CV}}\right) \approx 1$. Using these assumptions, Equation 3 becomes

$$
\frac{\left(P_{C V, i}-P_{C V, f}\right) V_{C V}(1)}{T_{C V}} \approx \frac{\Delta V_{S T P} P_{S T P}}{T_{S T P}}
$$

Substituting Equation 5 into Equation 4 gives

$$
P_{S C, f}=P_{S C, i}+\frac{\Delta V_{S T P} P_{S T P}}{T_{S T P}} \cdot \frac{T_{S C} x_{C V}}{V_{S C}}
$$

Equation 6 will be the starting point for calculating the measured inert pressure in the SC. The mole fraction of He-3, $x_{\mathrm{He}}$, in a pure tritium gas sample as a function of time, is given by

$$
x_{H e}=\frac{H e_{0}+T_{0} \cdot\left[1-e^{(-0.05624 \cdot t)}\right]}{H e_{0}+T_{0} \cdot\left[1-0.5 \cdot e^{(-0.05624 \cdot t)}\right]}
$$

where $T$ is the number of tritium atoms, the subscript 0 refers to the number at time zero, and $t$ is time in years. Finally, for an absorption test with pure tritium at time zero $\left(\mathrm{x}_{\mathrm{He}, 0}=0\right)$, the contribution of He-3 in the sample cell void space on the measured pressure is given by

$$
P_{S C, f}=P_{S C, i}+\frac{\Delta V_{S T P} P_{S T P}}{T_{S T P}} \cdot \frac{T_{S C}}{V_{S C}} \cdot\left[1-\frac{\left[1-e^{(-0.05624 \cdot t)}\right]}{\left.1-0.5 \cdot e^{(-0.05624 t)}\right]}\right.
$$

Equation 8 will be used to estimate the final pressure in the SC due to accumulated He-3.

Ultimately, the minimum absorption pressure that can be achieved is estimated by the sum of the partial pressures of $\mathrm{He}-3$ and the equilibrium pressure of the hydride as given by

$P_{m}=P_{S C, f}+P_{Q 2}$

Where $P_{m}$ is the measured pressure, $P_{S C, f}$ is the partial pressure of the inerts in the $\mathrm{SC}$ and $P_{Q_{2}}$ is the equilibrium pressure of the hydride.

\section{SAMPLE CALCULATION}

Consider the low pressure hydride zirconium. Below $550^{\circ} \mathrm{C}$, a two-phase region exists (Ref.1). A van't Hoff regression of data taken at $550^{\circ} \mathrm{C}, 525^{\circ} \mathrm{C}$, and $500^{\circ} \mathrm{C}$ at a hydrogen-to-zirconium $(\mathrm{H} / \mathrm{Zr})$ atomic ratio of 1.0 , gave $\Delta \mathrm{H}$ equal to $-192.41 \mathrm{~kJ} / \mathrm{mol}^{-\mathrm{H}_{2}}$ and $\Delta \mathrm{S}$ equal to $157.75 \mathrm{~J} / \mathrm{mole}-\mathrm{H}_{2} / \mathrm{K}$. Using these parameters, equilibrium hydrogen plateau pressures can be estimated at various temperatures.

A one gram $\mathrm{Zr}$ sample contained in a tubular sample cell with a nominal $10 \mathrm{cc}$ void volume will be loaded with $1.23 \mathrm{~Pa}-\mathrm{m}^{3}$ of tritium to achieve a loading of $1.0 \mathrm{~T} / \mathrm{M}$ for this example. The final contributions of accumulated helium-3 in the $\mathrm{SC}$ void, $\mathrm{P}_{\mathrm{SC}, \text { f, will be calculated for }}$ various times using Equation $8 . \quad \mathrm{P}_{\mathrm{SC}, \mathrm{i}}$ will be set to zero indicating an initially evacuated sample. The times required for helium-3 buildup to equal the equilibrium pressure of the sample can be calculated by setting $\mathrm{P}_{\mathrm{SC}, \mathrm{f}}$ equal to the Zr-hydride equilibrium pressure calculated using the previously defined van't Hoff parameters. The results are presented numerically in Table 1 and 
TABLE I. Zirconium Hydride Pressures and Tritium Decay Results at Various Temperatures

\begin{tabular}{|c|c|c|c|c|c|c|}
\hline \multirow[b]{2}{*}{$\mathrm{T}(\mathrm{C})$} & \multirow{2}{*}{$\begin{array}{l}\text { Hydrogen } \\
\text { Equilibrium } \\
\text { Pressure (Pa) }\end{array}$} & \multirow{2}{*}{$\begin{array}{l}\text { Decay Time to } \\
\text { Equal } \mathrm{H}_{2} \\
\text { Equilibrium } \\
\text { Pressure }\end{array}$} & \multicolumn{4}{|c|}{ Pressure of He-3 Accumulated in the SC Void (Pa) } \\
\hline & & & $1 \mathrm{sec}$ & $10 \mathrm{sec}$ & $100 \mathrm{sec}$ & $1000 \mathrm{sec}$ \\
\hline 600 & $5.5 \mathrm{E}+01$ & $82.9 \mathrm{~min}$ & $1.4 \mathrm{E}-02$ & $1.4 \mathrm{E}-01$ & $1.4 \mathrm{E}+00$ & $1.4 \mathrm{E}+01$ \\
\hline 550 & $1.1 \mathrm{E}+01$ & $17.6 \mathrm{~min}$ & $1.3 \mathrm{E}-02$ & $1.3 \mathrm{E}-01$ & $1.3 \mathrm{E}+00$ & $1.3 \mathrm{E}+01$ \\
\hline 500 & $1.7 \mathrm{E}+00$ & $3.0 \mathrm{~min}$ & $1.3 \mathrm{E}-02$ & $1.3 \mathrm{E}-01$ & $1.3 \mathrm{E}+00$ & $1.3 \mathrm{E}+01$ \\
\hline 450 & $2.3 \mathrm{E}-01$ & $25 \mathrm{sec}$ & $1.2 \mathrm{E}-02$ & $1.2 \mathrm{E}-01$ & $1.2 \mathrm{E}+00$ & $1.2 \mathrm{E}+01$ \\
\hline 400 & $2.0 \mathrm{E}-02$ & $2.5 \mathrm{sec}$ & $1.1 \mathrm{E}-02$ & $1.1 \mathrm{E}-01$ & $1.1 \mathrm{E}+00$ & $1.1 \mathrm{E}+01$ \\
\hline 350 & $1.3 \mathrm{E}-03$ & $0.17 \mathrm{sec}$ & $1.0 \mathrm{E}-02$ & $1.0 \mathrm{E}-01$ & $1.0 \mathrm{E}+00$ & $1.0 \mathrm{E}+01$ \\
\hline 300 & $5.1 \mathrm{E}-05$ & $7.1 \mathrm{~ms}$ & $9.3 \mathrm{E}-03$ & 9.3E-02 & $9.3 \mathrm{E}-01$ & $9.3 \mathrm{E}+00$ \\
\hline
\end{tabular}

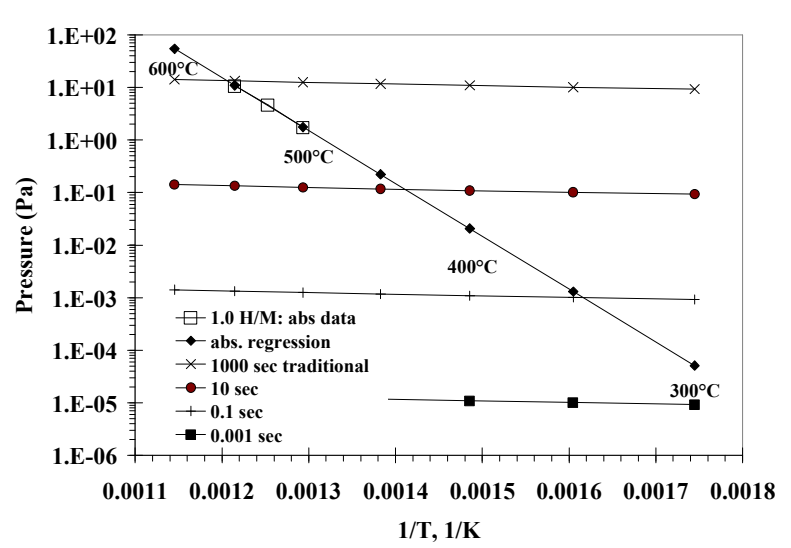

Figure 1. Comparison of Zr-hydride pressures to sample cell He-3 pressures at various times

graphically in Figure 1. Literature data are presented as unfilled boxes; extrapolated values are presented as filled diamonds. Intersections of the van't Hoff regression with horizontal lines represent conditions where $\mathrm{P}_{\mathrm{Q} 2}=\mathrm{P}_{\mathrm{SC}, \mathrm{f}}$.

The calculations show that 1 ppm helium-3 can be generated in as little as 280 seconds and can have a significant impact on the final measured pressure. Figure 1 shows that even under the best imaginable absorption test conditions, the helium-3 pressure in the $\mathrm{SC}$ will easily exceed $1.33 \mathrm{~Pa}$ corresponding to a $\mathrm{Zr}-\mathrm{H}$ equilibrium pressure of roughly $500^{\circ} \mathrm{C}$. Estimation of the tritium absorption pressure by subtraction of a calculated helium3 pressure from the measured pressure would not produce meaningful results due to measured pressure typically being one or more orders-of-magnitude greater than the true hydride absorption pressure.

Examination of Equation 8 shows that changing the amount of gas absorbed or the SC volume will alter the calculated helium-3 pressure proportional to the change of that parameter, but not the orders-of-magnitude change needed to disregard the partial pressure of inerts in the SC.

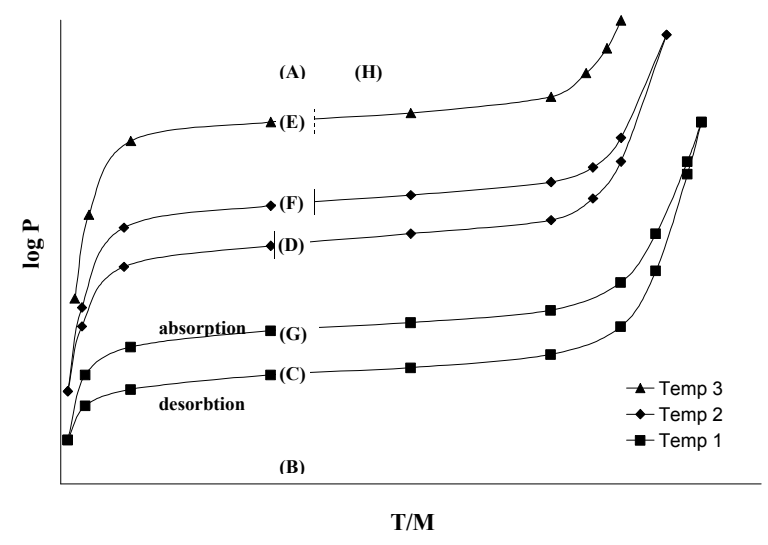

Figure 2. Graphical Depiction of Modified Approach

\section{ALTERNATE METHOD}

The following steps are depicted graphically in Figure 2. A CV is loaded to a predetermined pressure corresponding to a target $\mathrm{T} / \mathrm{M}$ load for an absorption equilibrium measurement using a typical Sievert's type manifold. By the time tritium is delivered to the $\mathrm{CV}$, allowed to equilibrate, and exposed to the low pressure hydride at Temperature 1, significant levels of helium-3 will have been generated in the gas phase. Assuming the sample is not prematurely blanketed by inerts and the tritium equilibrium pressure is sufficiently low, greater than $99.9 \%$ of the gas in the $\mathrm{CV}$ will be absorbed onto the hydride. Accumulated inerts in the SC contribute to an artificially high absorption equilibrium pressure (A). The $\mathrm{SC}$ is allowed to cool and the inerts are evacuated (B). Because the vast majority of the hydrogen in the $\mathrm{CV}$ is absorbed onto the sample and the very low equilibrium pressure of the material at the reduced temperature, evacuation of the inerts does not lead to high $\mathrm{T} / \mathrm{M}$ uncertainty. Following evacuation, the $\mathrm{SC}$ is reheated to Temperature 1 (C), then Temperature 2 (D), and finally Temperature 3 (E) to collect desorbtion data. Absorption 
data $(F, G)$ are then collected by allowing the sample to cool stepwise to Temperatures 2 and 1.

Because the amount of tritium present in the gas phase is orders of magnitude less than that when the sample was initially loaded, the partial pressure of helium-3 will be proportionally less over the same time interval. It is important to note that the sample may be cooled and evacuated whenever inert buildup is a concern. If data at additional $\mathrm{T} / \mathrm{M}$ values are desired, the sample may be cooled, inerts evacuated, and loaded with additional tritium $(\mathrm{H})$ to continue the experiment.

Selection of the thermal step size is critical when shifting from desorbtion to absorption data collection as shown in the exaggerated hysterisis loops given in Figure 3. If a desorbtion data point $(\mathrm{X})$ is collected at Temperature 1, cooling the sample to Temperature 2 will result in a pressure decrease to point $(Z)$, instead of the desired data point (Y). Too small of a step size will produce a data point within the hysterisis loop as opposed to on the loop boundary. If the apparent sample volume is known at the temperature range in question, a simple PVT calculation will determine whether pressure decreases are due to gas absorption or simply temperature decreases. Conversely, if the thermal step size is too large, excess helium-3 will be generated in the gas phase, limiting the minimum pressure that can be studied.

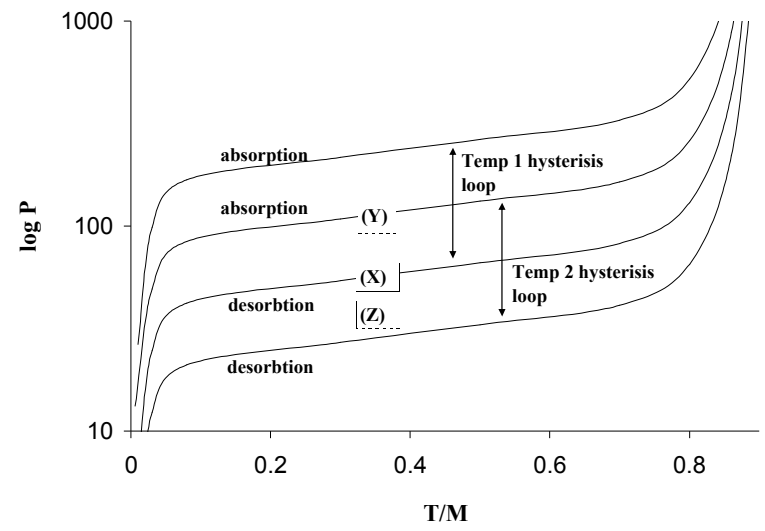

Figure 3. Overlapping Hysterisis Loops

\section{APPLICATION TO PREVIOUS EXAMPLE}

Application of this approach to the $\mathrm{Zr}$ example above allows equilibrium data collection at considerably lower temperatures and pressures than the traditional direct approach. Assuming an average tritium gas phase age of 1000 seconds, the partial pressure of helium-3 will be approximately equal to the equilibrium pressure of the $\mathrm{Zr}$ at $550^{\circ} \mathrm{C}$. By cooling the sample to a relatively low temperature, say $50^{\circ} \mathrm{C}$, the sample may be evacuated without removing tritium from the solid phase (the calculated equilibrium pressure is less than 1.3E-18 $\mathrm{Pa}$ ). Following evacuation, the sample may be heated to a desorbtion pressure of approximately $133 \mathrm{~Pa}$. If the heated sample volume plus ambient manifold volume is $100 \mathrm{cc}$, roughly $1.2 \mathrm{E}-2 \mathrm{~Pa}-\mathrm{m}^{3}$ tritium gas will be present. Assuming the same 1000 second average gas phase age, the helium-3 partial pressure will be about $0.1 \%$ of that present during the initial loading. This will allow collection of absorption data approximately three orders of magnitude lower than possible using the traditional method. A graphical comparison of the traditional and modified approaches is given in Figure 4.

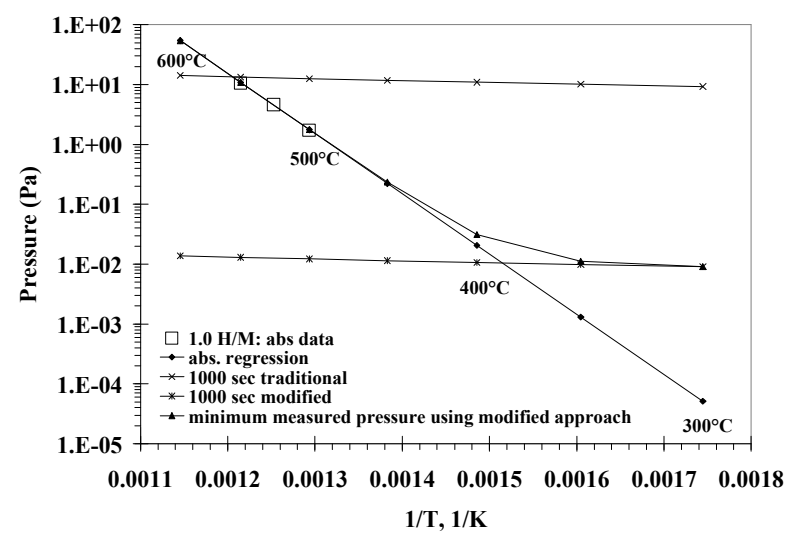

Figure 4. Comparison of Traditional and Modified Approach at 1000 seconds

\section{CONCLUSIONS}

High purity gas is essential when performing absorption isotherms on low pressure hydride/getter materials. Due to helium-3 generation, direct collection of tritium absorption equilibrium data in the sub-torr range using a standard Sievert's type manifold is not practical. The overwhelming majority of gas phase helium-3 will be generated during the initial loading of the sample. Cooling the sample and evacuating impurities will not impact sample loading and will allow studying equilibrium pressures lower than possible using a traditional approach. Both absorption and desorbtion data can be obtained by taking appropriately sized thermal steps.

\section{REFERENCES}

1. W. M. Mueller, J. P. Blackledge, and G. G. Libowitz, editors. Metal Hydrides, p. 247, Academic Press, NY (1968). 